\title{
Best Mentoring Practices of Design Education at the Design High School Level and Instructional Resources
}

\author{
Hyun-Kyung Lee ${ }^{1}$ \\ ${ }^{1}$ Department of Human Environment, Design, Yonsei University, Seoul, Korea \\ Correspondence: Hyun-Kyung Lee, Department of Human Environment, Design, Yonsei University, 134 \\ Sinchon-dong, Seodaemun-gu, Seoul, 120-749, Korea. Tel: 82-2-2123-3092. E-mail: \\ hyunkyung.lee@yonsei.ac.kr
}

$\begin{array}{lc}\text { Received: January 2, } 2012 & \text { Accepted: February 24, } 2012 \quad \text { Published: June 1, } 2012 \\ \text { doi:10.5539/jel.v1n1p67 } & \text { URL: http://dx.doi.org/10.5539/jel.v1n1p67 }\end{array}$

The research is financed by the National Research Foundation of Korea Grant funded by the Korean Government (NRF-2011-35C-G00067).

\begin{abstract}
This article examines education practices intended to maximize the effectiveness of education in a design high school. Consistent with the requirements of national curricula, design high schools seek to optimize formal education by developing programs that provide a framework for teaching students the skills and knowledge needed to become active participants in planning and shaping their world. Numerous studies have concluded that design-based learning and mentoring relationships are a significant factor in succession planning, career development, and skill development. To research the role and value of design-based learning and mentoring relationship, the author recorded observations of visiting speakers from various disciplines who presented design-based learning experiences and mentoring system to design education classes at The Design High School in Los Angeles. Because the purpose of this study was to investigate educational practices of a design high school, to explore the role and importance of design-based learning and mentoring relationship, and to generate theoretical concepts of the ways in which such a high school is structured, a grounded theory approach was used to guide and interpret the collection and analysis of the data. Three primary methods were used for data collection: document analysis, observation, and interviews. The finding shows that design education can enhance learning in K-12 students. The author concludes by suggesting educational strategies that could be incorporated into a design high school curriculum.
\end{abstract}

Keywords: design education, Design-Based Learning (DBL), mentoring relationship, art center college of design, design high school education

\section{Introduction}

The author argues that students of today learn more effectively through the use of pedagogical practices that emphasize holistic thinking, active learning, team-orientation, visual communication and problem solving (Lee, 2009). The defining qualities of the millennial generation - those who started college in 2000 and were raised in the digital age - are consistent with these practices. Through research conducted at Art Center College of Design, The Design High School, as well as at peer schools in the U.S. and around the world, it is clear that strategies of design-based learning and mentoring relationship are more aligned with the cognitive processes attributed to students of the millennial generation (and those younger) than the strategies used in traditional schools. In other words, these new forms of learning are a better fit with the way today's high school and college students receive and process information, and are thus likely to produce higher success rates. Thus, design-based learning and mentoring relationship present new ways for realizing long-term academic goals and learning outcomes in particular for students of this generation and for those in the foreseeable future. The purpose of this article is to investigate best practices of design education at the high school level and to propose instructional resource examples of design education to $\mathrm{K}-12$ teachers.

When students are engaged in the design process, they are learning to observe, identify needs, seek and frame problems, work collaboratively, explore solutions, weigh alternatives, and communicate their ideas verbally and 
visually (Davis, Hawley, McMullan, and Spilka, 1997). The design process includes periods of self-assessment, critiques of works in progress, revisions, and opportunities for reflection (Nelson, 1984). Perhaps most importantly, learning through the design process engages students in active, creative and participatory exercises that appeal to the expectations that today's K-12 students have come to expect from their formative experience in digital media.

\section{What is DBL and Mentoring Relationship?}

Design-Based Learning (DBL) experience teaches students a problem-solving process that they can adapt to many situations (Davis, Hawley, McMullan, and Spilka, 1997). As John Dewey noted as far back as 1910, a critical failing of American schools was that they were conceived as a place where lessons were learned and habits formed that were separate from daily life. (Dewey, 1910). But as Dewey argued in My Pedagogic Creed, "the only true education comes through the stimulation of the child's powers by the demands of the social situation in which he finds himself." (Dewey, 1897). Whether focusing on everyday problems in immediately observable settings or projecting problems into the future, using design in the classroom builds bridges between school and life, which makes the learning process not only more memorable but more meaningful as well. Rather than beginning with abstractions, design-based learning demands that students derive concepts and principles from real encounters with their world. They learn the unfamiliar by finding it in or comparing it to what they already know through experience (Davis, Hawley, McMullan, and Spilka, 1997).

Design is inherently interdisciplinary by virtue of the multiple skill sets and forms of knowledge required to solve real-world problems. It combines concepts and practices found in art as well as in the natural and social sciences inasmuch as it cannot be separated from social, cultural, and physical contexts in which these problems arise. In the same way, design-based methodologies encourage systems thinking: because no single problem can be understood or resolved in isolation from its real-world contexts, a variety of factors and contingencies must be taken into account in a holistic, interconnected approach. Likewise, the most successful uses of design in the classroom are also interdisciplinary, holistic and systems-based. While there still remains a tendency to think of design as the purview of the art or industrial arts class - the result of historical high school curricula that focused only on visual aesthetics or pre-professional, "applied arts" training - in recent years design has broadened its scope to include creative, problem-solving approaches across the curriculum. Design activities empower students to make decisions, modeling the responsibilities of adult citizens, as Dewey demanded from education over a century ago. Through design, students learn the consequences of such decisions and prepare to be active participants in shaping their physical, social, and cultural environments (Anderson, 2000).

Herbert Simon famously defined design as "devising courses of action aimed at changing current situations into preferred ones." (Simon, 1996). This means that the logic and reasoning process of design is abductive rather than deductive or inductive, as described by the linguist Charles Sanders Peirce (Brent, 1993). Abductive logic is the process of imagining a hypothetical situation that does not yet exist. By definition a creative, constructive process, it has been adopted by designers to distinguish their activity from the inductive or deductive logic of science, which can only explain things as they are. For Simon (1996) as well, design is transformative, and it brings the meaning and satisfaction of having improved our "current situations." The pedagogical appeal of the abductive experience in the classroom cannot be underestimated, especially for millennial students who demonstrate a fundamental commitment to social justice and a perhaps overly optimistic faith in their ability to effect positive change. Belief in the relevance of education and the transformative power of one's actions create a powerful incentive (or "stimulation," to use Dewey's word) for students to engage in the project-based learning of the design process.

Numerous studies have concluded that mentoring relationships are a significant factor in succession planning, career development, and skill development (Liang, Spencer, Brogan, and Corral, 2008). Mentoring is a process of forming a relationship between a more experienced, seasoned and wiser person (mentor) who helps a less experienced person (mentee) develop in some specified capacity. In this case mentor was the Art Center speakers and mentee was the Los Angeles Design High School.

\section{Partnership with the Design High School, Los Angeles}

High schools that offer an academic emphasis in architecture and design, very often charter schools, are appearing more frequently in cities across the United States (Lee, 2009). This trend may be due to the belief that design and innovation are more important in enhancing economic growth and quality of life. China, Korea and Singapore have recently launched significant national efforts to increase and improve design education in their countries, largely driven by the promise of competitive economic advantage in the future. In the United States, under the Obama administration, there is at least the beginning of a dialogue about the importance of creativity 
in our schools. In April, 2010, Secretary of Education, Arne Duncan (2010) stated that "arts education is essential to stimulating the creativity and innovation that will prove critical to young Americans competing in a global economy." If Duncan is right, high schools that offer architecture, design and arts curricula, as well as those that embed design-based learning in the classroom, may very well represent the future promise of American education and indeed of the new economy that will need to emerge from the current recession.

In 2003, Art Center College of Design in Pasadena, California, started a partnership to develop a charter school that would incorporate design-based learning and the design process mentoring relationship across its curriculum. Despite the laborious process and at times interruptive practices of the Los Angeles Unified School District, the Design High School in Los Angeles opened its doors in the fall of 2006. The new charter school thrived for four years, increasing its student body each year, achieving higher attendance rates and standardized test scores than its public school counterparts. Most significantly, it attracted many "problem students" disaffected by the public school curriculum who thrived on the active, project-based curriculum and as a result found their first academic success at The Design High School. Unfortunately, the struggling California state economy resulted in budget cuts that forced the school to close in 2010. Nonetheless, this bold experiment in design-based learning remains an important and useful case study.

\section{About the Design High School, Los Angeles}

The Design High School in Los Angeles was a free public charter school (although dependent on state support) that was sponsored by Art Center College of Design. The collaborative relationship and dynamic interaction between Art Center designers and instructors trained in design-based learning and mentoring relationship evolved and deepened into a powerful and unique curriculum that presented an exciting new way of teaching and learning that can be widely replicated.

The mission of The Design High School was to empower 9th-12th grade students from the underserved areas of Los Angeles to become lifelong learners, problem-solvers and creative leaders. The ambitious vision of the charter school program was to create inspired leaders who are exceptionally intelligent, skilled and talented, and to whom others look for direction; to educate students who make things possible that could not otherwise be done; to cultivate powerful communicators who are articulate, engaging and influential, able to shape other people's thinking and emotions; and finally, to nurture engaged, creative, resourceful learners who know how to find solutions-learners who create things that previously did not exist (abductive reasoning).

The schools premise was that learning to think as a designer gives students the experience and skills they need for productive, transformative decision-making. At The Design High School, the concepts and practice of design were used to deliver a rigorous and relevant college preparatory and career-oriented curriculum. In this context, design as a way of thinking and an approach to creative problem-solving functioned as a methodology to engage students in higher-level critical thinking while embedding and addressing grade-level, California standards-based, academic content. The Design High School emphasized that when classrooms are student-centered, the role of the teacher and the relationship between student and teacher are transformed. The student becomes the focus of the teaching and learning process, and the teacher becomes the facilitator, a relationship consistent with the emerging field of "co-design," in which designers and clients (or users) cooperate in a shared design process led by the designers' expertise but dependent on the clients' needs and aspirations (Brent, 1993).

In this approach, teaching is thus transformed from "telling about" to "doing" through student participation in complex, real world projects. Authentic activities are used not only to teach subject matter, but also to foster understanding across the curriculum. The student becomes empowered to take responsibility for his or her own learning. Understanding how to learn and taking control of one's own learning creates a personal investment and commitment that promotes a more engaged, active classroom, as well as a habit of life-long learning. The students' ability to discover what they want to learn, and how to acquire this knowledge, is necessary to thrive in the 21 st century.

At The Design High School, students engaged in hands-on, meaningful, shared experiences that became the common language among students and instructors. Thus, the school provided a forum in which students developed their own unique voices. Hands-on projects that integrated the required curriculum engaged students and maximized learning. As students applied basic skills and knowledge from different subject areas, they were challenged to think critically at the highest level. A sampling of observations from students demonstrates the students' rejuvenated interest in learning:

Referring to Design High, one student said, "I wanted to get a good career involving art, and this looked like a great opportunity to improve my work." Another student remarked, "I have made lots of friends and learned to be open about my art." 
Yet another student explained, "There is no fighting; this school is really safe. People care about each other. . Coming from a school with almost 40 kids per classroom, it's great to be in such a small and close-knit environment. . This school has given me so many opportunities and has given me so many useful skills."

As one of the Design High teacher concluded, "Students learn more when they enjoy their classes. They have better options after they graduate."

\section{Method: A program of design education at the Design High School}

Every last Friday of the month, from 10am to 3pm, two Art Center student speakers were sent to the art class of The Design High School. The student speakers, representing different majors, presented their portfolios and talked about their respective disciplines, also describing their own school experiences and high school lives. Also as a mentor, the student speaker talked to each high school students about design related skills and knowledge. The process of selecting student speakers began with recommendations from each Art Center department chair. These candidates were interviewed by the author, who selected those most passionate about their work and articulate in their communication. The following notes were recorded by the author during the student speakers' classes:

\subsection{Procedure Example 1: The Design High School Friday Event (March 27, 2009)}

Last Friday (March 27, 2009), Demetrius May (Illustration Major) led the morning periods and Robby Smith (Interaction Design Major) guided the afternoon periods. Demetrius May brought many examples of his work: silk-screened and commercial product designs and T-shirts designed for a retail shop. (Coincidently, the fact that the shop was owned by the parent of one of the DHS students generated a great deal of excitement about the T-shirts. Demetrius donated about twenty of the T-shirts that he had designed to the students.) He also shared the story of his high school life and his graffiti-painting experiences, giving the students detailed information about Art Center's illustration program.

Similarly, Robby Smith talked about a more theoretical and philosophical approach to design. As an example, he referred to the advantages and disadvantages of the digital clock as compared to the analog clock: the digital clock could be read more easily, whereas the analog clock could more easily be used to visualize the entire day. Another example given was text messaging: although it may seem convenient, the message's intended tone of voice may be lost. The presentation seemed a good chance to reflect upon the relationship between human development and technological advances.

The students loved the classes, and the art teacher, Carol Reynolds, appreciated the interactive nature of the visiting speakers' presentations. Some of the students submitted feedback (thank you letters) intended for speakers who had visited the high school previously. These letters were scanned and attached as a PDF file below. Also included are photos taken during the classes.

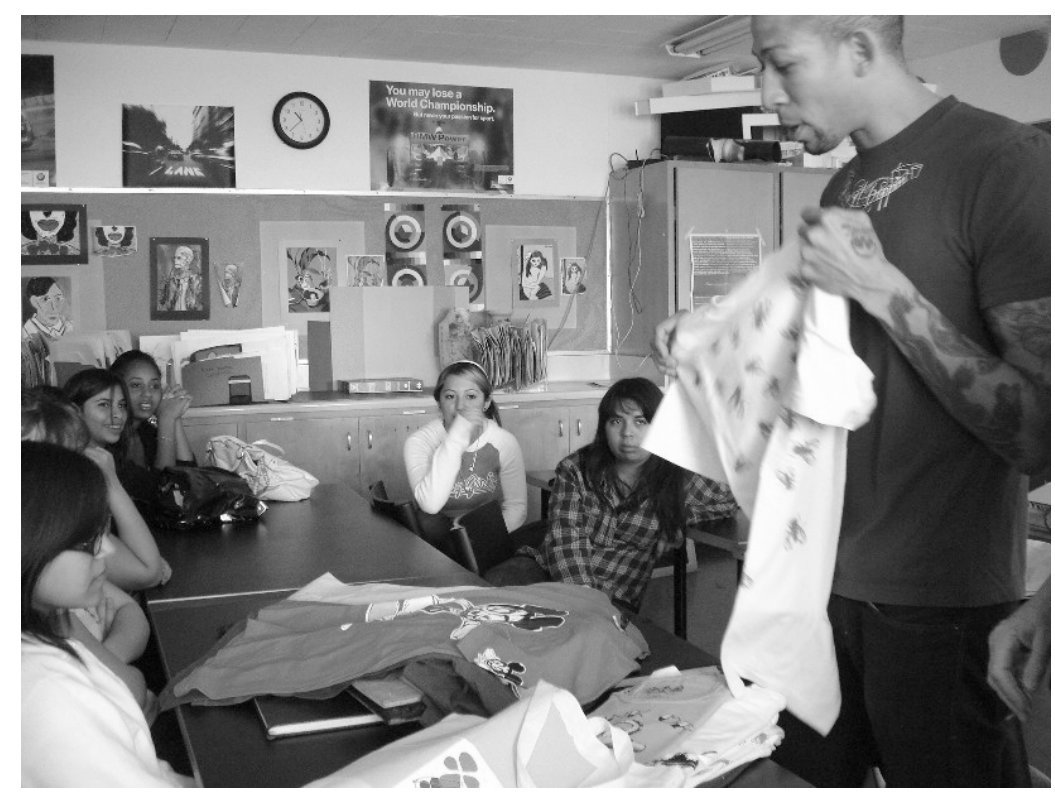

Figure 1. The design high school Friday event I (March 27, 2009) 


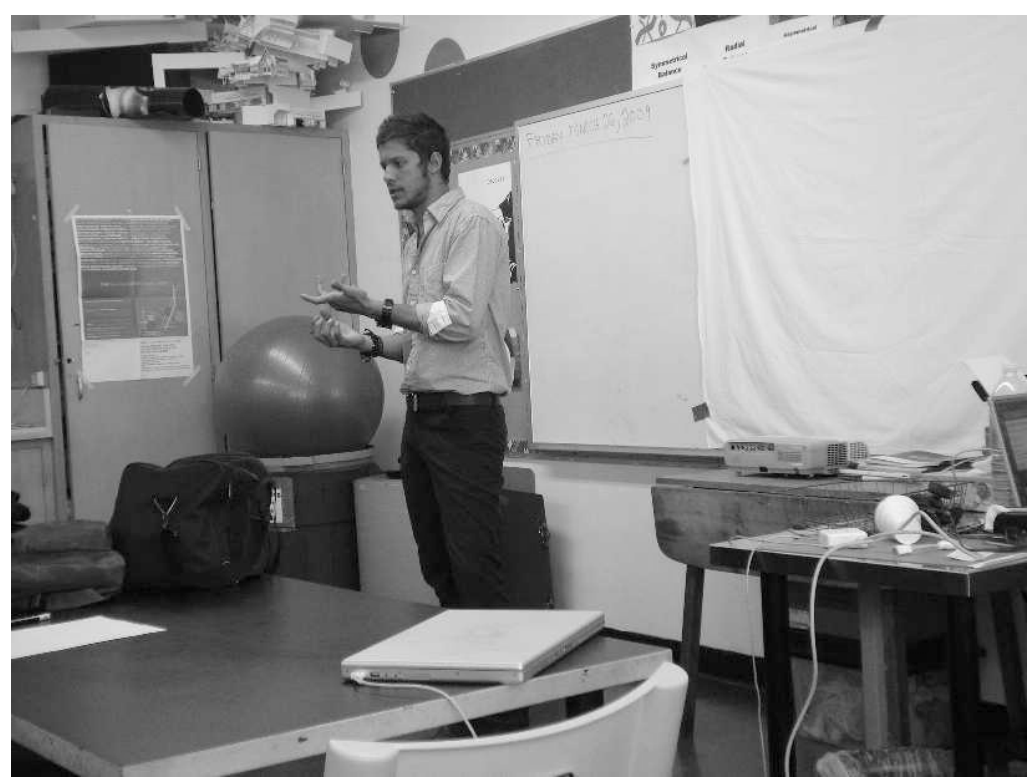

Figure 2. The design high school Friday event II (March 27, 2009)

\subsection{Procedure Example 2: The Design High School Friday Event (May 8th, 2009)}

Last Friday (May 8th, 2009), an Art Center student speaker from the Entertainment Department, John Park, led the afternoon periods. He had majored in product design for two years and had then transferred into entertainment design. Currently, he is taking two years off from his education to work for DreamWorks, Electronic Arts, and Scott Robertson's design studio.

John showed his portfolio to the students. It featured animation images mostly, such as Shrek, Peter Pan, and Macho Man, as well as architectural images. He discussed the step-by-step animation design process from prototype, with initial sketches, to final work, with rendered characters done on Photoshop. He added explanations of the characters' positions, fashions, and patterning. He also suggested to the students that, when they draw something, they should ask themselves a series of questions: What creature or vehicle do I want to draw? Why draw this creature or vehicle? What is its purpose? What material and functional ability does the character have? He concluded this discussion by stating, "Research first and then draw. Do not just draw without planning or thinking." The students nodded their heads in agreement.

John said that he spent his high school life in Chino Hills and Riverside. He drew pictures all the time. One student asked him to identify the source of his inspiration. He replied that observing nature influenced and informed his work.

John also demonstrated how to draw with a marker. The students requested a mechanical monkey and a zombie lady. He instantly drew a thumbnail sketch of each character and then, in no more than 12 minutes for each drawing, blocked in the completed image.

At this time, many students handed in their "thank you" letters written to the previous visiting Art Center speakers (Demetrius May and Robby Smith). These were scanned and attached as a PDF file below. Included are photos taken during the classes. 


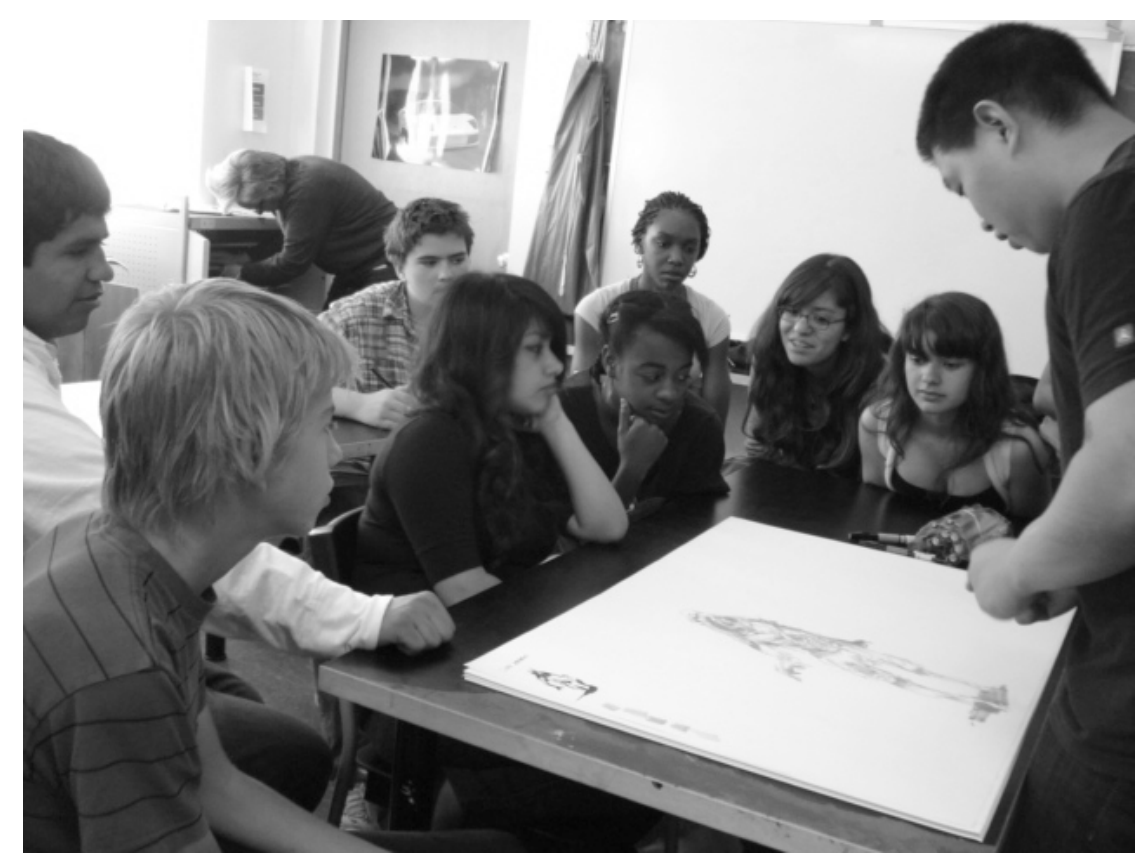

Figure 3. The design high school Friday event III (May 8th, 2009)

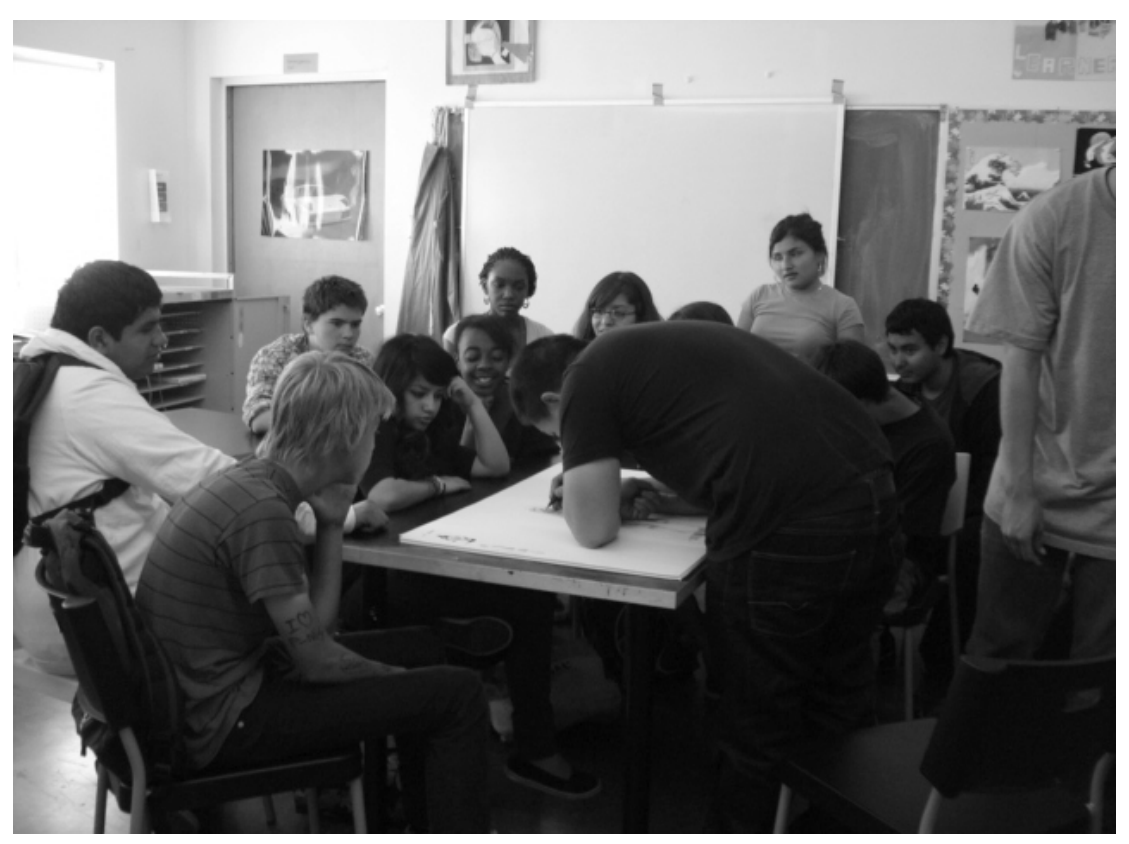

Figure 4. The design high school Friday event IV (May 8th, 2009) 


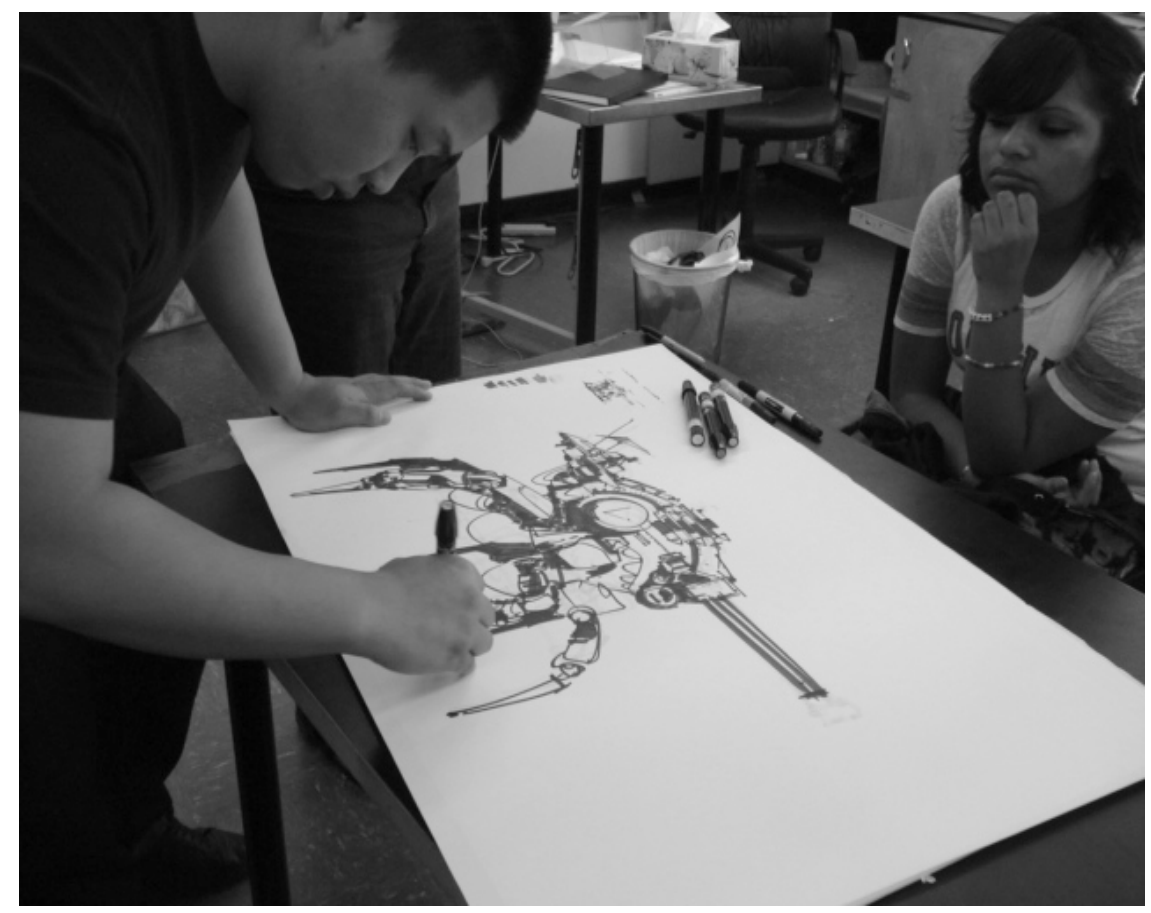

Figure 5. The Design High School Friday Event V (May 8th, 2009)

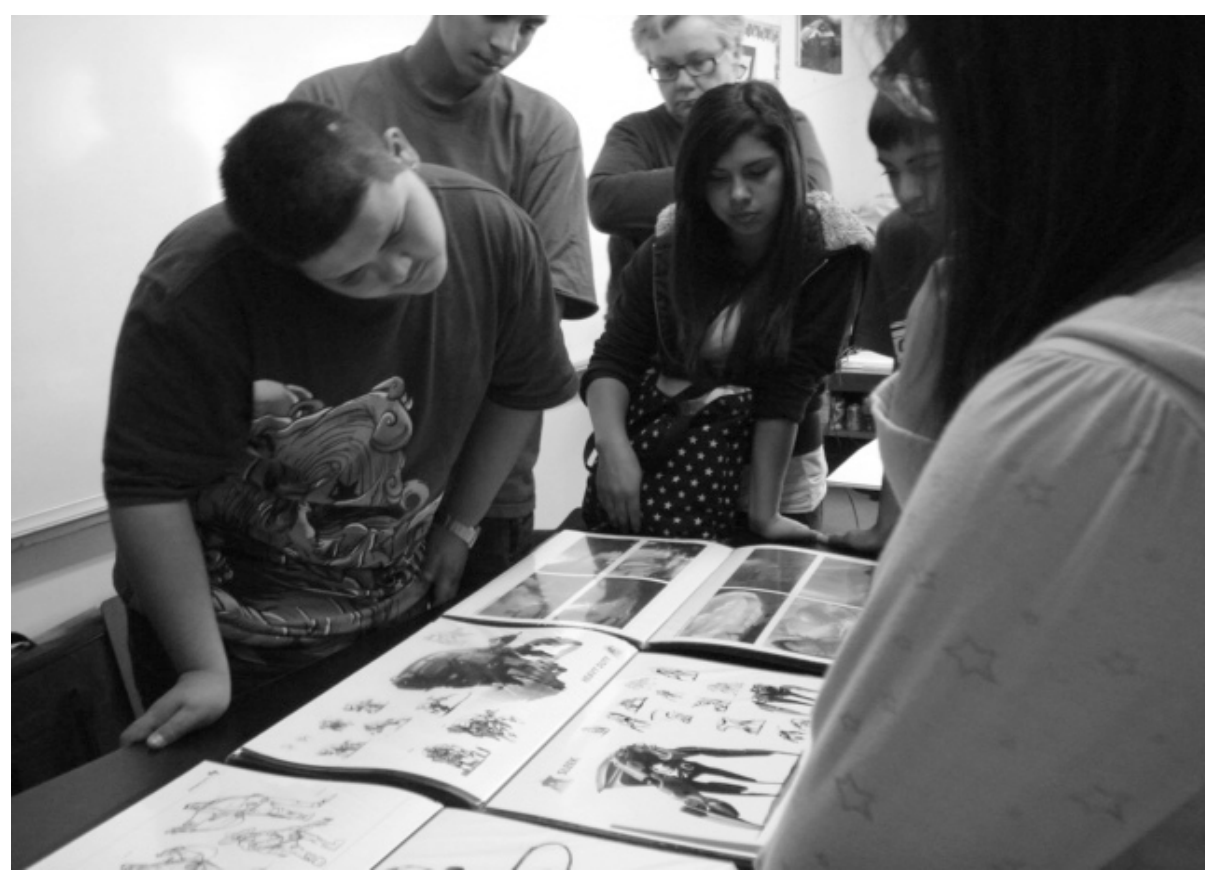

Figure 6. The Design High School Friday Event VI (May 8th, 2009) 


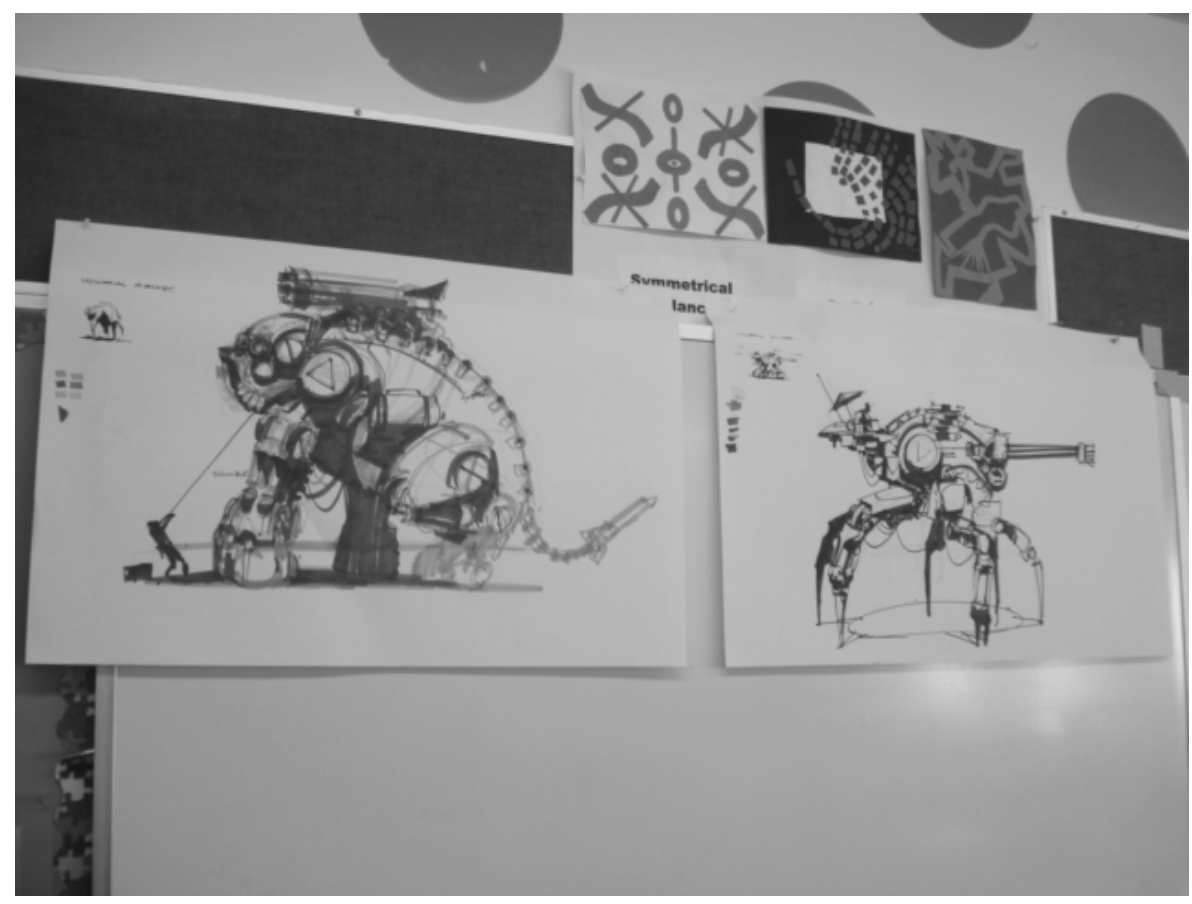

Figure 7. The Design High School Friday Event VII (May 8th, 2009)

\section{Findings}

To research the role and value of design-based learning, the author recorded observations of visiting speakers from various disciplines who presented design-based learning experiences and mentoring relationship to design education classes at The Design High School in Los Angeles.

Numerous studies have concluded that mentoring relationships are a significant factor in succession planning, career development, and skill development (Liang, Spencer, Brogan, and Corral, 2008). Mentoring is a process of forming a relationship between a more experienced, seasoned and wiser person (mentor) who helps a less experienced person (mentee) develop in some specified capacity. In this case mentor was the Art Center speakers and mentee was the Los Angeles Design High School. Mentoring is both value and career-oriented. Value-oriented in that a mentee's character and values are developed and career-oriented because the mentee is taught the skills and given information that is relevant to his/her career. In the remainder of this article the author clarified the notion of mentoring, and encouraged its use in organizations (Liang et al, 2008). The author identified the barriers to mentoring, clarified the roles of both mentors and mentees, and suggested an implementation process for a mentoring program.

From the positive feedback and responses offered in the "thank you" letters, observations and interviews, it is clear that the students learned a great deal from the Art Center speakers. The program conducted by the author utilized an approach to learning in which design was an integral part of the curriculum and pedagogy. Innovative student speakers explored with their students the mode of inquiry used by graphic designers, product designers, entertainment designers, interior designers, film designers, and architects. The student speakers used active-learning experiences that modeled the cognitive and social problem-solving demands of adult life. The program offered the genuine promise of preparing students to think constructively about their future careers as informed professionals. Through observation and interviews at a design high school art class, this research presents findings demonstrating the use of design experiences in education that can provide students with learning construct for the future.

In our research at the Art Center College of Design in Pasadena, California, one of the leading design schools in the world, as well as at peer schools in the USA and around the world, it is apparent that the strategies of mentoring relationship and design-based learning are also more consistent with the cognitive processes we attribute to students of the millennial generation and younger. In other words, these new forms of learning are a better fit with the way high school and college students today receive and process information, and are thus likely to produce higher success rates. The year-old Design High School in Los Angeles already reports significantly higher attendance rates than the Los Angeles Unified School District average (Lee \& Breitenberg, 
2010).

\section{Conclusions}

In every aspect of our lives, we make design decisions that reflect our personal, social, political, aesthetic, and economic desires. As such, these decisions reflect our aspirations and ideals, as well as our compromises. The purpose of design education is to provide a framework for teaching young people the skills needed to become active, informed participants in planning and shaping their world. In looking at the design of cities, students explore the social, physical, and cultural environments that shape human behavior (Davis \& Moore, 1992). In analyzing visual communication, students decode meaning found within the relationship between word and image. Such assignments integrate skills in the language arts, art, history, and technology. While active involvement in the design process usually characterizes most design-based learning and mentoring relationship, these reflective activities also form a foundation for the development of discriminating consumers who make critical choices in their adult lives (Lee, 2009).

Through the example of three Art Center student speakers, it is clear that students are deeply engaged by the design process through a variety of project-based learning activities and mentoring relationship. Student speakers introduced silk-screened and commercial product designs and T-shirts designed for a retail shop, shared graffiti-painting experiences, reflected on the relationship between human development and technological advances, discussed the step-by-step animation design process from prototype, with initial sketches, to final work, and demonstrated how to draw with a marker. Through these presentations, students learned observe, identify needs, seek and frame problems, work collaboratively, explore solutions, weigh alternatives, communicate their ideas verbally and visually, and give feedback to the Art Center student speakers on their own initiative.

The student speaker program included periods of self-assessment, critiques of works in progress, revisions, and opportunities for reflection on the design process. Learning through the design process engages students in active, creative and participatory exercises that appeal to the learning experiences that today's K-12 students have come to expect from their formative experience in digital media. Additionally, it is clear that strategies of design-based learning and mentoring relationship are more consistent with the cognitive processes attributed to students of the millennial generation (and those younger) than the pedagogical strategies used in traditional schools. Design-based learning and mentoring relationship are consonant with the way today's high school and college students receive and process information.

Through its presentations, The Design High School Friday Events program enabled students to better understand design and apply its processes to their lives. Such a program can engage other schools in the design process as well, promoting skills such as active observation, critical discussion, strategies for visual communication, and critique. K-12 classroom teachers can bring the program into their classrooms to enhance the study of other disciplines, ultimately increasing academic performance and connecting school curricula to real life issues and experiences. Design-based learning and mentoring relationship present new ways for realizing long-term academic goals and learning outcomes in particular for students of this generation and for those in the foreseeable future.

Design educators must approach learners as active participants and adapt the creative, abductive design process of creating new realities in real world contexts, and by forming and reforming categories and structures that work to explain the phenomenal world and allow the learner to interact with it more effectively. Perhaps the last remark about our research should be left to a famous educator who lived over 2,500 years ago:

I hear and I forget.

I see and I remember.

I do and I understand.

-Confucius

\section{References}

Anderson, T. (2004). Why and How We Make Art with Implications for Art Education. Arts Education Policy Review, 105(5), 31-38.

Anderson, T. (2003). Art Education for Life. International Journal of Art and Design Education, 22(1), 58-66. http://dx.doi.org/10.1111/1468-5949.00339

Anderson, T. (2000). Using art criticism strategies in ethnographic research. Visual Arts Research, 26(2), 80-87. University of Illinois Press. 
Brent, J. (1993). Charles Sanders Peirce: A Life. Bloomington, Indiana: Indiana University Press.

Davis, M., Hawley, P., McMullan, B., \& Spilka, G. (1997). Design as a catalyst for learning. Virginia: Association for supervision and Curriculum Development.

Davis, M., \& Moore, R. (1992). Education through design: The middle school curriculum. Raleigh, North Carolina: School of Design/North Carolina State University.

Dewey, J. (1897). My pedagogic creed. School Journal, 54(1), 77-80.

Dewey, J. (1910). My pedagogic creed. Chicago, Illinois: A. Flanagan Company.

Duncan, A. (2010). Looking in the mirror: Address by the Secretary of Education to parenting magazine's mom congress on education and learning. U.S. Dept. of Education.

Eisner, E. (1998). The enlightened eye: Qualitative inquiry and the enhancement of educational practice. New York: Macmillan Publishing Company.

Lee, H. K. (2009). Design museum management: Examining the structure and policies of the Cooper-Hewitt National Design Museum with implications for best practice. Saarbrücken, Germany: VDM Verlag Dr. Müller.

Lee, H. K., \& Breitenberg, M. (2010). Education in the new millennium: The case for design-based learning. International Journal of Art and Design Education, 29(1), 54-60. http://dx.doi.org/10.1111/j.1476-8070.2010.01631.x

Nelson, D. (1984). Transformations: Process and theory. Los Angles, California: City Building Education.

Liang, B., Spencer, R., Brogan, D., \& Corral, M. (2008). Mentoring relationships from early adolescence through emerging adulthood: A qualitative analysis. Journal of Vocational Behavior, 72, 168-182. http://dx.doi.org/10.1016/j.jvb.2007.11.005

Sanders, L. (1999). How technology is changing institutional research. San Francisco: CA: Jossey-Bass Publishers.

Simon, H. A. (1996). The sciences of the artificial. Cambridge, Massachusetts: MIT Press.

Strauss, A., \& Corbin, J. (1990). Basics of qualitative research: grounded theory procedures and techniques. Newbury Park, California: Sage. 